\title{
CHARGE syndrome: a review of the immunological aspects
}

\author{
Monica TY Wong ${ }^{1}$, Elisabeth H Schölvinck ${ }^{2}$, Annechien JA Lambeck ${ }^{3}$ and Conny MA van Ravenswaaij-Arts ${ }^{\star, 1}$ \\ CHARGE syndrome is caused by a dominant variant in the CHD7 gene. Multiple organ systems can be affected because of \\ haploinsufficiency of CHD7 during embryonic development. CHARGE syndrome shares many clinical features with the 22q11.2 \\ deletion syndrome. Immunological abnormalities have been described, but are generally given little attention in studies on \\ CHARGE syndrome. However, structured information on immunological abnormalities in CHARGE patients is necessary to \\ develop optimal guidelines for diagnosis, treatment and follow-up in these patients. Here, we provide an overview of the current \\ literature on immunological abnormalities in CHARGE syndrome. We also explore immunological abnormalities in comparable \\ multiple congenital anomaly syndromes to identify common immunological phenotypes and genetic pathways that might regulate \\ the immune system. Finally, we aim to identify gaps in our knowledge on the immunological aspects in CHARGE syndrome that \\ need further study.
}

European Journal of Human Genetics (2015) 23, 1451-1459; doi:10.1038/ejhg.2015.7; published online 18 February 2015

\section{INTRODUCTION}

Patients with a combination of coloboma and other multiple congenital abnormalities were first described in $1961 .{ }^{1,2}$ However, the association between coloboma, congenital heart defects and choanal atresia was first recognized by both $\mathrm{Hall}^{3}$ and Hittner $e$ e $a l^{4}$ in 1979. Then in 1981, Pagon et al proposed the acronym CHARGE, which stands for the following symptoms: Coloboma of the eye, Heart defects, Atresia of the choanae, Retardation of growth and/or development, Genital abnormalities, and Ear abnormalities (external, middle and inner ear including deafness). The incidence of CHARGE syndrome (MIM\# 214800) is estimated at 1 in 15000-17000 newborns $^{6}$ and its clinical diagnosis is based on the criteria proposed by Blake et $\mathrm{al}^{7}$ or by Verloes. ${ }^{8}$ Since 2004, when the major genetic cause of CHARGE syndrome was identified as a dominant variant in the CHD7 gene (MIM\# 608892), which usually occurs de novo, CHARGE syndrome can also be diagnosed by molecular diagnostics. A variant in $C H D 7$ can be found in over $90 \%$ of all children who fulfil the clinical diagnostic criteria. ${ }^{6,9-11}$ The CHD7 gene encodes a member of the chromodomain helicase DNA-binding protein family that regulates the transcription of genes during embryonic development. Haploinsufficiency of CHD7 affects multiple organ systems, including the heart, the inner ear and the eye. There is no clear genotype-phenotype correlation, but variants leading to a premature stop codon are, in general, associated with a more severe phenotype than variants with a non-truncating effect, that is, missense variants. ${ }^{12}$

Since the genetic cause of CHARGE syndrome was identified, its phenotype has been further explored. In addition to the above symptoms, other common clinical features of CHARGE syndrome are: absent or hypoplastic semicircular canals, cranial nerve dysfunction (including facial nerve palsy), cleft lip and/or palate, anosmia, feeding difficulties and skeletal abnormalities. ${ }^{8,9,13}$ Furthermore, deficits in the immune system have been described in CHARGE patients, which might lead to morbidity and even mortality. ${ }^{14}$

Here, we provide an overview of the current literature on immunological dysfunction in CHARGE syndrome. We also explore what can be learned from the clinical overlap between CHARGE syndrome and other multiple congenital anomaly (MCA) syndromes. Do these syndromes share immunological phenotypes? Last but not least, we try to identify gaps in our knowledge that need further study.

\section{METHODS}

A systematic search via the online database PubMed of publications on immunological aspects of CHARGE syndrome was performed (Supplementary 1). All patients with a proven variant in CHD7, which affects the normal function of the protein, were included in our review. We also decided to include articles prior to the identification of $\mathrm{CHD} 7$ as the causative gene, in order to have a complete overview. Before $\mathrm{CHD} 7$ was discovered, some patients with CHARGE syndrome were described as having DiGeorge syndrome (\#MIM 188400) or as having DiGeorge syndrome with CHARGE association. For our review, we only selected patients from these papers who fulfilled the diagnostic criteria of Blake et a ${ }^{7}$ and/or Verloes, ${ }^{8}$ and in whom a deletion of 22q11.2 (the cause of DiGeorge syndrome) had been excluded or was unknown. The titles and abstracts of English language articles were reviewed for relevance. Relevant articles were studied in detail and their reference lists were scanned for additional publications (Supplementary 2). Information on the thymus and the results of the following immunological tests were used: lymphocyte subset phenotyping (if available, absolute numbers of T-, B- and NK-cells), quantitative immunoglobulin analysis, and T-cell function by response on mitogens (phytohaemagglutinin). Owing to frequently missing absolute values and the differences in reporting laboratory results, especially whether age-related reference values were used or not, we decided to follow the interpretations of the authors instead of using our own cutoff values. For papers that only mentioned laboratory results without interpretation, we used the age-related reference values according to Comans-Bitter et al ${ }^{15}$ for interpretation.

\footnotetext{
${ }^{1}$ University of Groningen, University Medical Centre Groningen, Department of Genetics, Groningen, The Netherlands; ${ }^{2}$ University of Groningen, University Medical Centre Groningen, Department of Paediatrics, Section Infectious Diseases and Immunology, Groningen, The Netherlands; ${ }^{3}$ University of Groningen, University Medical Centre Groningen, Department of Medical Immunology, Groningen, The Netherlands

${ }^{*}$ Correspondence: Professor CMA van Ravenswaaij-Arts, University Medical Centre Groningen, Department of Genetics, CB51, P.0. Box 30.001, Groningen 9700 RB, The Netherlands. Tel: +31 50 3617100; Fax: +31 50 3617230. E-mail: c.m.a.van.ravenswaaij@umcg.nl

Received 12 May 2014; revised 18 December 2014; accepted 25 December 2014; published online 18 February 2015
} 


\section{RESULTS}

\section{The collected cohort}

All literature on immunology or immune dysfunction in CHARGE syndrome consists of case reports or retrospective studies. We identified 26 publications, comprising 59 patients in total ('our collected cohort'), which fulfilled our inclusion criteria (Table 1). Thirty-six of $59(61 \%)$ patients had a proven variant in CHD7 with functional effect (Table 1A). Detailed information on the variant in CHD7 has been reported for 23 of these patients and all variants were known to lead to a premature stop in CHD7 (data not shown). The remaining 23 of 59 (39\%) patients fulfilled the clinical criteria of CHARGE syndrome, but the results of CHD7 analysis (Table 1B) or the results of both $\mathrm{CHD} 7$ analysis and 22q11.2 deletion testing (Table 1C) were unknown. The median age at which immunological tests $(n=64)$ were performed in our collected cohort was 15 weeks (range, 1 day to 8 years). In some patients, immunological tests were performed at different ages.

\section{Immunological abnormalities reported in CHARGE syndrome}

Clinical presentation related to immune abnormalities included recurrent otitis media in 4 patients $(6.8 \%)$, sinusitis in 2 patients (3.4\%), conjunctivitis in 2 patients (3.4\%), dermatitis in 4 patients $(6.8 \%)$, infections of the respiratory tract in 6 patients $(10 \%)$, including pneumonia in $3(5.1 \%)$, and sepsis in $5(8.5 \%)$ of 59 patients. ${ }^{14,16-22}$ Three patients had features resembling Omenn syndrome, a form of severe combined immune deficiency, characterized by autoimmune-like features and macular skin rash due to the formation of abnormal, autoreactive T cells. ${ }^{18,23}$ Other severe presentations included a patient with recurrent oral candidiasis, recurrent severe infections, and septic shock due to colonization with multiresistant species of Pseudomonas aeruginosa, Stenotrophomonas maltophilia and Acinobacter (Janda et al, ${ }^{22}$ Table 1B); another patient with severe general dermatitis and ulcers of the colon (Boudny et al, ${ }^{24}$ Table 1B); and a patient with CHARGE association and T-cell deficiency with a chronic viral infection of the gut (Wood et al, ${ }^{25}$ Table 1C).

Information on T-cell numbers were reported in 44 of 59 patients and in 24 of 36 patients with a proven variant in CHD7. As shown in Table 1, 35 of the $44(80 \%)$ patients with available information on T-cell numbers had low or absent T-cell numbers. Of the 35 patients, 1 patient had T-cell lymphopenia and a transient B-cell lymphopenia, which normalized with ageing. ${ }^{26-28}$ Thymic aplasia was reported in 27 of 59 patients and in 16 of 36 patients with a proven variant in CHD7. T-cell lymphopenia in our collected cohort was associated with thymic aplasia or hypoplasia in 21 of $22(95 \%)$ patients. ${ }^{18-36}$ T-cell function by response on mitogens was available for 28 of 59 patients and of these 28 patients $24(86 \%)$ had a low or absent response on mitogen. For 23 of $26(88 \%)$ patients, T-cell lymphopenia was concomitant with T-cell dysfunction. ${ }^{14,17,18,20,22-31,33,35-37}$

In our collected cohort, B- and/or NK-cell numbers were reported in only 29 of 59 patients, and of these 29 patients, 1 had low B-cell numbers, 1 had high B-cell numbers, 1 had low NK-cells numbers and 3 had high NK-cell numbers. The reported B- and NK-cells numbers of other patients were normal. ${ }^{14,23,26-28,34-36}$

Immunoglobulin levels were reported in 33 of 59 patients and in 20 of 36 patients with a proven variant in CHD7. Hypogammaglobulinaemia was reported in 20 of $33(61 \%)$ patients and measured along with T-cell lymphopenia in 14 of 18 (78\%) patients. ${ }^{14,17,22-29,35,36}$ Thirteen of 33 (39\%) patients with known immunoglobulin levels had IgG deficiency and 2 of these patients had received immunoglobulin replacement therapy. ${ }^{14,16-18,22-29,38}$ Of these 13 patients with IgG deficiency, 6 had recurrent or chronic infections and 1 had absent specific antibody responses. ${ }^{14,16-18,22,24,25}$ Isolated immunoglobulin deficiencies were rarely reported in CHARGE syndrome. One patient with an isolated IgG2 subclass deficiency ${ }^{17}$ and two patients with an isolated IgA deficiency ${ }^{14}$ were reported. One patient developed low IgG and elevated IgE while the T-cells normalized. ${ }^{18}$

Jyonouchi et $a^{14}$ reported on the largest cohort of patients with CHARGE syndrome $(n=25)$ proven by a variant in CHD7, and retrospectively collected their immunological data. However, lymphocyte subset phenotyping and quantitative immunoglobulin analysis were performed in only nine and eight patients, respectively. They concluded that a greater proportion of CHARGE patients had immunological abnormalities than previously thought (lymphopenia in $60 \%$ and humoral defects in $16 \%$ of patients, respectively). They confirmed the overrepresentation of T-cell dysfunction and also reported two patients with a severe combined immune deficiency phenotype.

In conclusion, T-cell lymphopenia is common (80\%) in CHARGE patients and is associated with a reduced T-cell function and hypogammaglobulinaemia, but normal B-cell and NK-cells numbers. Thymic aplasia or hypoplasia might be the underlying cause of T-cell lymphopenia, leading to increased frequencies of infection and other clinical presentations.

According to Jyonouchi et $a l,{ }^{14}$ immune dysfunction in CHARGE might contribute to the mortality of the syndrome. Two patients died from infectious complications and two patients with a confirmed severe combined immune deficiency phenotype died from respiratory failure. Assing et $a^{\beta 4}$ reported a patient with CHARGE syndrome who had severely reduced thymic function and a severe lymphopenia, but showed a functional and diverse T-cell receptor repertoire, and a good response to vaccines. An uneventful infection history was reported up to the age of 34 months, but thereafter the clinical status is unclear.

\section{Immunological abnormalities reported in overlapping MCA syndromes}

CHARGE syndrome overlaps clinically with other MCA syndromes (see Figure 1)..$^{39}$ The most remarkable phenotypic overlap is with 22q11.2 deletion syndrome (\#MIM 192430, TBX1), including the DiGeorge phenotype, where immunodeficiency is an important symptom. Congenital heart defects, cognitive and motor delay, hearing loss, external ear anomaly, cleft lip and palate, growth deficiency, and renal anomaly are seen in both syndromes. ${ }^{14,39}$ The total absence of the thymus, and therefore complete T-cell lymphopenia (DiGeorge phenotype), is rare and is seen in less than $1.5 \%$ of patients with 22q11.2 deletion syndrome. ${ }^{40}$ Patients with the typical 1.5 or $3.0 \mathrm{Mb}$ deletion of $22 \mathrm{q} 11.2$ rarely show the full presentation of the syndrome and only a minority develop opportunistic infections. Much more common is a phenotype with T-cell lymphopenia $(67 \%)^{41}$ combined with mild to moderate functional immunological impairment which improves with age. This T-cell lymphopenia mostly present as frequent viral infections during childhood, with or without secondary bacterial infections, but can also remain clinically unrecognized. ${ }^{40,41}$ Owing to their abnormal palatal anatomy, which may compromise drainage, most patients are susceptible to upper airway infections, as is also seen in patients with CHARGE syndrome. There are more publications on immunoglobulin abnormalities in 22q11.2 deletion syndrome compared with CHARGE syndrome. ${ }^{42,43}$ Recent studies indicate that the antibody deficiency in 22q11.2 deletion syndrome is likely to be underestimated. ${ }^{44,45}$ Patel et al ${ }^{44}$ have reported immunoglobulin deficiency in the largest cohort $(n=855)$ to date and concluded that $6 \%$ of the patients over the age of three had 


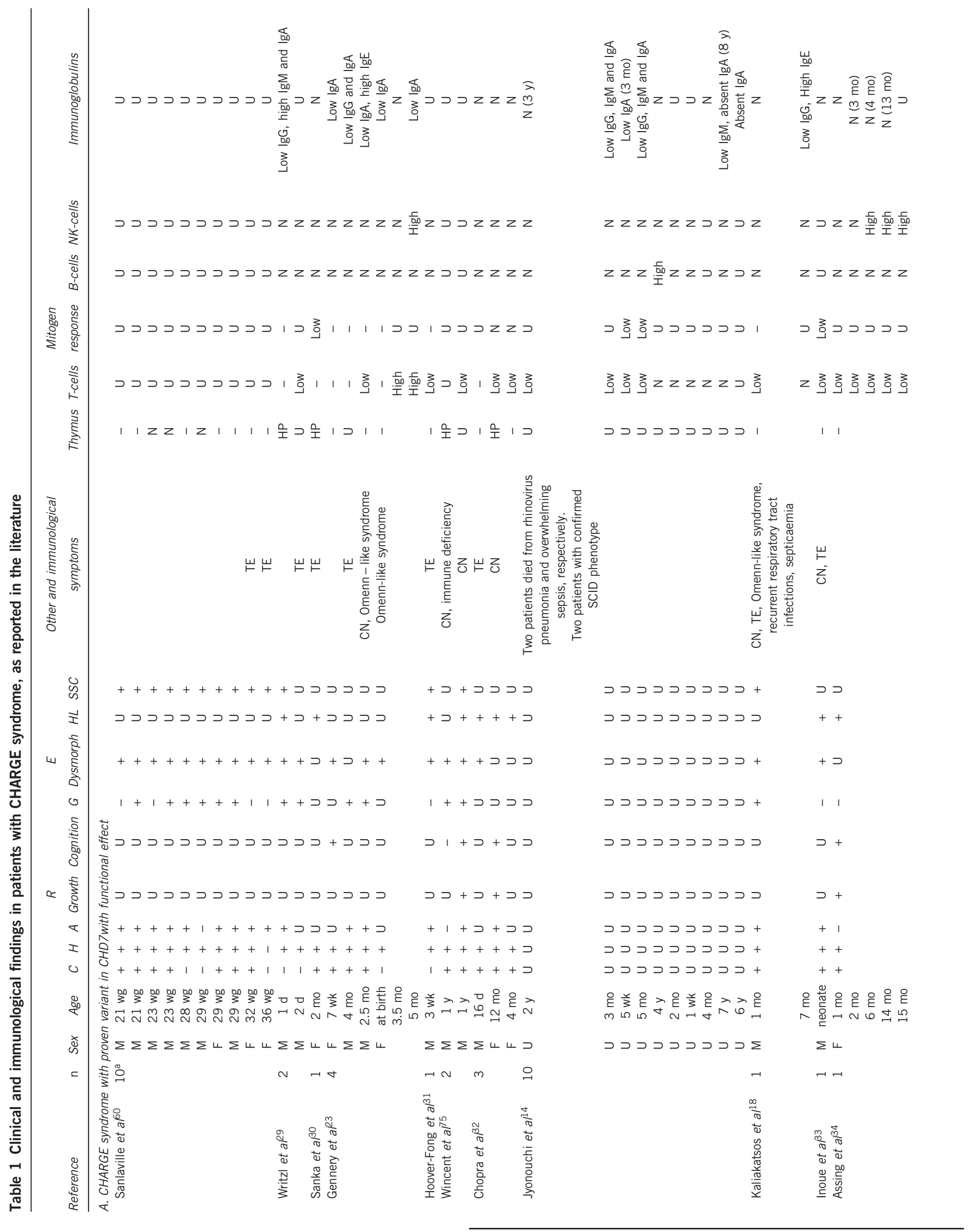




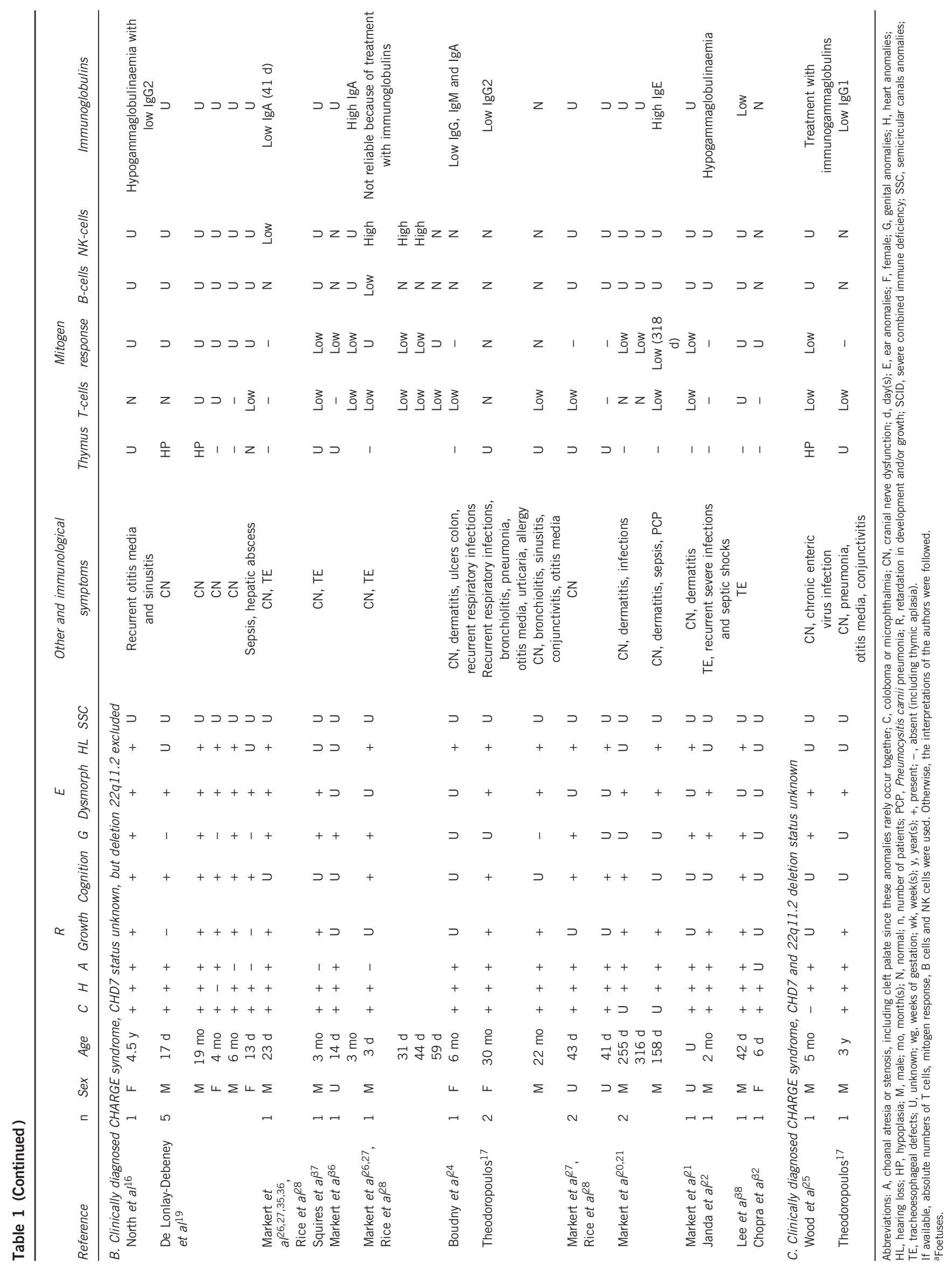




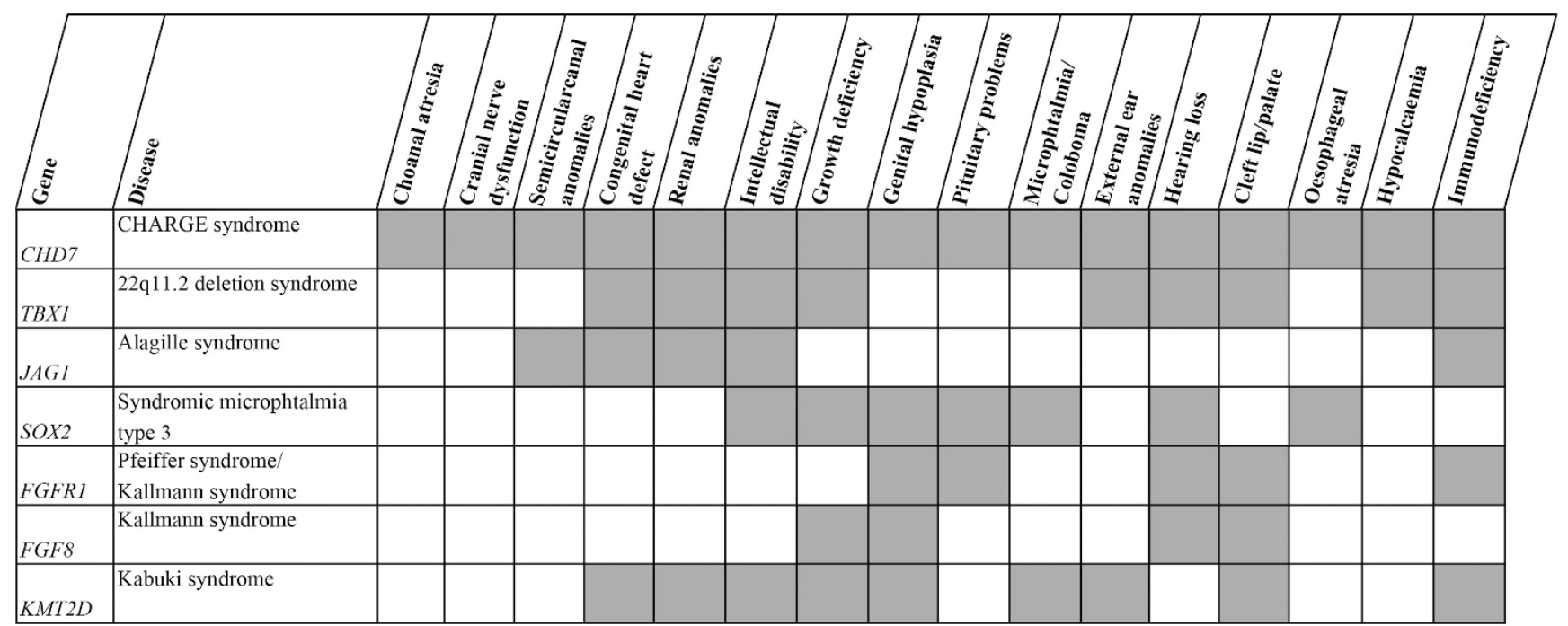

Figure 1 Clinical overlap of CHARGE syndrome with other MCA syndromes. The overlapping clinical features of CHARGE syndrome with other MCA syndromes are shown. All the genes mentioned, or their proteins, have been associated with CHD7. Adapted from Corsten-Janssen et al. ${ }^{14}$

hypogammaglobulinaemia, $19 \%$ of the total cohort had a low level of IgG and $2-3 \%$ of the patients were receiving immunoglobulin replacement therapy. Björk et al ${ }^{45}$ found that 6 of 26 adult patients (23\%) had low immunoglobulin levels. Autoimmune diseases, like rheumatoid diseases and idiopathic thrombocytopenia purpura, are seen in approximately $10 \%$ of patients with 22q11.2 deletion syndrome, ${ }^{46}$ whereas no autoimmune diseases were seen in the CHARGE syndrome patients, although 3 of 59 (5\%) patients with CHARGE syndrome had an Omenn-like syndrome, which has autoimmune-like features. An explanation of the autoimmune predisposition in 22q11.2 deletion syndrome might be a reduced level of natural regulatory T-cells (nTreg). ${ }^{47}$ These nTregs are important in the maintenance of self-tolerance, that is, suppression of the immune response against self-antigens. In our collected cohort of CHARGE patients, nTreg levels were mentioned in only two patients: one patient had few nTregs (no value was mentioned) ${ }^{23}$ and the other patient had higher proportions of nTregs compared with two adult controls. ${ }^{34}$ So CHARGE syndrome shares a large clinical overlap with 22q11.2 deletion syndrome and this seems to be also true for the prevalence of T-cell lymphopenia, leading to susceptibility for viral (and secondary bacterial) infections.

Immunological functions in other overlapping MCA syndromes are less well described. Alagille syndrome (\#MIM 118450), caused by variants in $J A G 1$, shares abnormalities in the semicircular canals, heart defects, renal anomalies and intellectual disabilities with CHARGE syndrome. ${ }^{39}$ Recurrent ear and respiratory tract infections are seen in about a quarter of patients with Alagille syndrome. ${ }^{48}$ The underlying immunological dysfunction was described in one paper as a diminished T-helper 1 response. ${ }^{49}$

Patients with Pfeiffer syndrome (\#MIM 101600, FGFR1) have overlapping features with CHARGE syndrome regarding cleft-lip and/or palate and hearing loss. ${ }^{39}$ The immunological function in 12 patients with craniofacial malformation syndromes, including Pfeiffer syndrome, was studied by Scheuerle et al. ${ }^{50}$ Unfortunately, they did not specify the immunological dysfunction per syndrome. However, seven patients were tested for T-cell numbers and T-cell lymphopenia was reported in one patient, decreased T-helper cells in three patients and decreased T-killer cells in three patients. Three patients had additional abnormalities in immunoglobulin counts and in lymphocyte stimulus and response function. Two were brothers, who both had Pfeiffer syndrome.

Kabuki syndrome (\#MIM 147920, KMT2D) has the following clinical overlap with CHARGE syndrome: cleft palate, mental retardation, short stature, genital hypoplasia, congenital heart defects, abnormalities of the eye and ear, renal abnormalities, scoliosis, and recurrent otitis media in infancy. ${ }^{51,52}$ Hoffman et al $l^{53}$ evaluated the immune condition of 19 patients with Kabuki syndrome and concluded that hypogammaglobulinaemia is a frequent finding (84\%). However, they tested lymphocyte subsets in only three patients, who showed no abnormalities in $\mathrm{T}$ - and B-cell numbers. Diminished T-cell function by response on phytohaemagglutinin and reduced naive T-helper cells were reported in one patient with Kabuki syndrome. ${ }^{54}$ Autoimmune disorders, including idiopathic thrombocytopenia purpura, are common in children with Kabuki syndrome. ${ }^{53,55}$

Thus, CHARGE syndrome and the clinically overlapping $22 \mathrm{q} 11.2$ deletion syndrome share an increased prevalence of T-cell dysfunction. Although T-cell dysfunction is only mentioned sporadically in Alagille syndrome, Pfeiffer syndrome and Kabuki syndrome, the clinical overlap of these syndromes with CHARGE syndrome indicates that their underlying genetic defects may result in shared embryonic pathways leading to T-cell abnormalities.

\section{DISCUSSION}

Does CHD7 share T-cell-related pathways with TBX1, JAGGED1, FGFR1 and MLL2?

The 22q11.2 region contains the TBX1 gene (\#MIM 602054), which has been identified as a candidate gene for most of the phenotypic features seen in the 22q11.2 deletion syndrome. ${ }^{40}$ The existence of a shared embryonic pathway or pathways of CHD7 and TBX1 has been studied for heart development ${ }^{56}$ and inner ear development ${ }^{57}$ in animal models. Both genes are expressed in the pharyngeal arches, of which the third and fourth arches contain the precursors of the thymic stromal cells. ${ }^{58-60}$ This might explain the shared underlying pathogenesis of abnormal thymic development and the high proportion of thymic aplasia (44\%) in our collected cohort with a proven $\mathrm{CHD} 7$ variant, which can lead to impaired T-cell development. However, it 
should be noted that the high proportion of thymic aplasia might be due to reporting bias.

It is also known that impaired T-cell development affects further maturation of the thymic stromal cells resulting in thymic epithelial cells with lack of Aire expression, a transcription factor that regulates the expression of self-antigens. These self-antigens are important for the deletion of autoreactive T-cells. ${ }^{61}$ McLean-Tooke et al ${ }^{47}$ suggested that the reduced number of nTregs seen in 22q11.2 deletion syndrome is related to thymic function and structure. So the autoimmune predisposition in 22q11.2 deletion syndrome might be explained by both impaired thymic and T-cell development. In CHARGE syndrome, only three patients were reported to have Omenn-like syndrome, which has autoimmune-like features. ${ }^{18,23}$ Well-defined autoimmune diseases have not yet been described in CHARGE syndrome, suggesting that the nTregs physiology might be different in CHARGE syndrome compared with 22q11.2 deletion syndrome. It would therefore be interesting to further study nTregs in CHARGE syndrome.

JAG1 (\#MIM 601920) is the underlying causative gene of Alagille syndrome and its protein JAGGED1 is a ligand of the Notch receptor. The Notch signalling pathway regulates cell-fate decisions during ontogeny, including the development of lymphoid cells, and there is accumulating evidence to suggest that Notch signalling is also involved in the maturation of peripheral T-cells. ${ }^{62,63}$ In animal models, Jagged 1 seems to play a role in the generation of regulatory T-cells. ${ }^{64,65} \mathrm{CHD} 7$ and JAG1 might be linked indirectly via SOX2 (\#MIM 184429), because Chd7 has been identified as a Sox 2 transcription cofactor in the regulation of common target genes including Jag1. ${ }^{66}$ Functional affective variants in SOX2 result in syndromic microphthalmia type 1, a phenotype that shares several features with CHARGE syndrome: microphthalmia, motor disability, neurocognitive delays, sensorineural hearing loss, oesophageal atresia, pituitary defects and gonadotropin deficiency. ${ }^{67}$ Immune dysfunction has not been described in syndromic microphthalmia type 1 thus far.

The underlying causative gene for Pfeiffer syndrome is FGFR1 (\#MIM 136350), encoding the fibroblast growth factor receptor 1 (FGFR1). FGFR1 and FGF8 (\#MIM 600483) are also involved in Kallmann syndrome, which shares features such as anosmia and hypogonadotropic hypogonadism with CHARGE syndrome. ${ }^{68}$ A common pathway for CHD7 and fibroblast growth factor 8 (FGF8)/FGFR1 has therefore been suggested. ${ }^{56,69,70}$ FGFR1 is expressed in a subset of T-cells and is believed to interact with the T-cell receptor to enhance the activation of T-cells. ${ }^{71}$

Table 2 Phenotypic comparison of our collected cohort with a proven variant in CHD7 compared with cohorts with a proven variant in CHD7 from the literature

\begin{tabular}{|c|c|c|c|}
\hline Feature & $\begin{array}{l}\text { Our collected } \\
\text { CHD7-positive } \\
\text { cohort }(n=36)\end{array}$ & $\begin{array}{l}\text { CHD7-positive cohort } \\
\text { from Bergman et al }{ }^{13} \\
(n=280)\end{array}$ & $\begin{array}{l}\text { CHD7-positive } \\
\text { cohort from Zentner } \\
\text { et } \mathrm{al}^{72}(\mathrm{n}=254)^{a}\end{array}$ \\
\hline \multirow[t]{2}{*}{ Coloboma } & $19 / 26^{b}$ & $189 / 234$ & $190 / 253$ \\
\hline & $73 \%(53-81 \%)^{c}$ & $81 \%(68-84 \%)$ & $75 \%$ \\
\hline \multirow[t]{2}{*}{ Heart defect } & $25 / 26$ & $191 / 252$ & $193 / 250$ \\
\hline & $96 \%(69-97 \%)$ & $76 \%(68-78 \%)$ & $77 \%$ \\
\hline \multirow[t]{2}{*}{ Choanal atresia } & $17 / 20^{d}$ & $99 / 179$ & $95 / 247$ \\
\hline & $85 \%(47-92 \%)$ & $55 \%$ & $38 \%$ \\
\hline \multirow[t]{2}{*}{ Cleft lip and/or palate } & No isolated cleft lip & $79 / 163$ & $79 / 242$ \\
\hline & & $48 \%(28-70 \%)$ & $33 \%$ \\
\hline \multirow[t]{2}{*}{ Growth retardation } & $3 / 3$ & $35 / 94$ & $101 / 141$ \\
\hline & $100 \%(8-100 \%)$ & $37 \%(13-79 \%)$ & $72 \%$ \\
\hline \multirow[t]{6}{*}{ Developmental delay } & Developmental delay & Delayed motor milestones & Developmental delay \\
\hline & $4 / 5$ & $147 / 149$ & $107 / 141$ \\
\hline & $80 \%(11-97 \%)$ & $99 \%(53-99 \%)$ & $76 \%$ \\
\hline & & Intellectual disability & \\
\hline & & $108 / 134$ & \\
\hline & & $74 \%(39-91 \%)$ & \\
\hline \multirow[t]{2}{*}{ Genital hypoplasia } & $13 / 20$ & $118 / 145$ & $116 / 187$ \\
\hline & $65 \%(36-81 \%)$ & $81 \%(42-90 \%)$ & $62 \%$ \\
\hline \multirow[t]{2}{*}{ External ear anomaly } & $21 / 21$ & $224 / 231$ & $214 / 235$ \\
\hline & $100 \%(58-100 \%)$ & $97 \%(80-98 \%)$ & $91 \%$ \\
\hline \multirow[t]{2}{*}{ Semicircular canal anomaly } & $14 / 14$ & $110 / 117$ & $94 / 96$ \\
\hline & $100 \%(39-100 \%)$ & $94 \%(39-98 \%)$ & $98 \%$ \\
\hline \multirow[t]{2}{*}{ Cranial nerve dysfunction } & $12 / 12$ & $173 / 174$ & Unknown \\
\hline & $100 \%(33-100 \%)$ & $99 \%(62-100 \%)$ & \\
\hline \multirow[t]{2}{*}{ Facial palsy } & $6 / 6$ & $80 / 121$ & $72 / 187$ \\
\hline & $100 \%(17-100 \%)$ & $66 \%(29-85 \%)$ & $39 \%$ \\
\hline \multirow[t]{2}{*}{ Tracheoesophageal anomaly } & $9 / 17$ & $42 / 146$ & $35 / 185$ \\
\hline & $53 \%(25-78 \%)$ & $29 \%(15-63 \%)$ & $19 \%$ \\
\hline
\end{tabular}

Adapted from Bergman et a/13 and Zentner et al. ${ }^{72}$

aThis cohort partially overlaps with the cohort of Bergman et a ${ }^{13}$ because the phenotypes of 64 of the patients in that study had been published previously.

bFrequencies are represented as the number of patients with a particular feature/the total number of patients that were tested for that particular feature.

${ }^{6}$ Frequencies are represented as the number of patients with a particular feature/the total number of patients that were tested for that
${ }^{C}$ The range of percentages presented between brackets was calculated as: (positive/total) $\times 100 \%$ - (positive +unknown/total) $\times 100 \%$.

${ }^{\mathrm{c}}$ The range of percentages presented between brackets was calculated as: (positive/total)
${ }^{\mathrm{d}}$ Cleft palate is included in choanal atresia since these anomalies rarely occur together. 
Kabuki syndrome is caused by variants in KMT2D (\#MIM 602113), affecting the function of a methyltransferase named MLL2 that is involved in transcriptional regulation. Recently, it has been shown that CHD7 interacts with the same transcriptional proteins as MLL2. ${ }^{52}$ It is unknown whether MLL2 plays a role in the immunological dysfunction in Kabuki syndrome, but it is possible that both MLL2 and CHD7 regulate expression of genes which are involved in the immune system.

CHD7 regulates the expression of genes and shares pathways with other regulatory proteins in embryonic development. ${ }^{39}$ The interaction of CHD7 with TBX1 and their role in thymic development has been well established in the literature. ${ }^{58-60}$ Evidence for the interaction of CHD7 with JAG1, FGFR1 and MLL2 during embryonic development, especially the development of the immune system, is less strong, but reports are emerging describing possible links in the genetic pathways. Although we only have detailed information on the variant in $\mathrm{CHD} 7$ for 23 patients, the fact that all reported variants lead to a premature stop in $\mathrm{CHD} 7$ is interesting, because truncating $\mathrm{CHD} 7$ variants are in general associated with a more severe phenotype. ${ }^{12}$

\section{Are certain phenotypic features more common in our collected cohort?}

In Table 2, we compare the clinical features of 36 patients in our collected cohort for whom a variant in $\mathrm{CHD} 7$ with functional effect had been proven (Table 1A) with two other cohorts described by Bergman et al. ${ }^{13}$ These two cohorts consist of 280 patients with a proven variant in CHD7 from Bergman et al ${ }^{13}$ and 254 patients from Zentner et al. ${ }^{72}$ Most features show similar frequencies in all three cohorts. We see a higher frequency in our collected cohort for heart defects ( $96 \%$ versus $76 \%$ and $77 \%$ ), choanal atresia ( $85 \%$ versus $55 \%$ and $38 \%$ ), and tracheoesophageal anomaly (53\% versus $29 \%$ and $19 \%)$. Facial palsy (100\%) and growth retardation (100\%) also seem to occur more frequently in our collected cohort, but we note that we only have clinical information on six and three patients, respectively. It should also be noted that two cases ${ }^{29}$ were included in all three cohorts. As the differences found might be due to the predominance of truncating variants in our cohort, Table 3 shows the phenotypic comparison of patients carrying variants leading to a premature stop in CHD7 in our collected cohort $(n=23)$ and in that of Bergman et al $^{12}(n=315)$. The frequencies between the two cohorts are more comparable than the frequencies shown in Table 2. However, Table 3 shows that our collected cohort still had a higher frequency for heart

Table 3 Phenotypic comparison of patients carrying a variant in CHD7 leading to a premature stop in $C H D 7$

Cohort of

\begin{tabular}{lcc} 
Feature & $\begin{array}{c}\text { Our collected } \\
\text { cohort }(\mathrm{n}=23)^{\mathrm{a}}\end{array}$ & $\begin{array}{c}\text { Bergman et all2 } \\
(\mathrm{n}=315)^{\mathrm{b}}\end{array}$ \\
\hline Coloboma & $16 / 23(69.6 \%)$ & $199 / 229^{\mathrm{c}}(86.9 \%)$ \\
Heart defect & $22 / 23(95.7 \%)$ & $212 / 257(82.5 \%)$ \\
Choanal atresia & $16 / 19^{\mathrm{d}}(84.2 \%)$ & $110 / 182(60.4 \%)$ \\
Cleft lip and/or palate & No isolated cleft lip & $80 / 144(55,6 \%)$ \\
External ear anomaly & $20 / 20(100 \%)$ & $217 / 221(98.2 \%)$ \\
Semicircular canal anomaly & $14 / 14(100 \%)$ & $121 / 121(100 \%)$ \\
Cranial nerve dysfunction & $5 / 5(100 \%)$ & $119 / 131(90.8 \%)$ \\
Tracheoesophageal anomaly & $8 / 16(50.0 \%)$ & $43 / 128(33.6 \%)$
\end{tabular}

The patients come from our collected cohort and the cohort of Bergman et al. ${ }^{12}$

a23 truncating mutations: 2 deletions, 8 frameshift mutations, 13 nonsense mutations.

b315 truncating mutations: 5 deletions, 139 frameshift mutations; 171 nonsense mutations.

cOwing to lacking clinical data, the number of patients is lower than the total number of patients.

${ }^{d}$ Cleft palate is included in choanal atresia as these anomalies rarely occur together. defects ( 95.7 versus $82.5 \%$ ), choanal anomaly ( 84.2 versus $60.4 \%)$, and tracheoesophageal anomaly (50.0 versus $33.6 \%)$. This is interesting because heart defects, choanal atresia and tracheoesophageal anomalies are all midline defects, including abnormal thymus development.

\section{Suggested future studies}

As shown in Table 1, the publications on immunology in CHARGE syndrome are scarce and most studies describe only one or a few patients, with data collected retrospectively. The differences in reporting the laboratory results, for example, absolute versus relative values, and the use of different reference values, whether age-related or not, make it difficult to draw conclusions. A limitation of our approach is that reporting bias might play a role, because most publications are case reports. Furthermore, the median age is quite young in our collected cohort. As the T-cell number may well improve with age, as has been shown in 22q11.2 deletion syndrome, ${ }^{73}$ our collected cohort might represent the more severe phenotypes.

We found lymphopenia in $80 \%$ of our collected cohort, which is in contrast to the $60 \%$ found in the study of Jyonouchi et al. ${ }^{14}$ Our higher percentage might reflect reporting bias. Another contrast is the reported prevalence of immunoglobulin abnormalities in 22q11.2 deletion syndrome of $6 \%$ in recent studies ${ }^{44,45}$ and $40 \%$ in older reports, ${ }^{42,43}$ with the prevalence of $61 \%$ in our collected cohort. However, we only had information on immunoglobulin levels from 33 of $59(56 \%)$ patients. Nonetheless, the percentages that we found indicate that immunological dysfunction in CHARGE syndrome might play a greater role in the phenotype than previously thought. There is a need to broaden our knowledge on the frequency and exact nature of immune abnormalities in CHARGE syndrome, including information on B- and NK-cells. As the pathophysiology of the immunological dysfunction in 22q11.2 deletion syndrome has been extensively studied, it is worthwhile to explore whether the same pathophysiology also applies to CHARGE syndrome.

Anatomical deviations, such as palatal defects, contribute to the susceptibility to infections and their duration by impeding drainage or clearance of infectious debris. It is important to know whether immunological issues complicate the severity of infections in order to optimize care management in patients. This is especially true for children with CHARGE syndrome, who have other co-morbidities (such as heart defects and tracheoesophageal defects) that require operative procedures, because these also constitute risk factors for infections.

Because immunological problems might contribute to the morbidity and even the mortality of patients with CHARGE syndrome, timely diagnosis of an immune dysfunction is relevant. Information on the type of immune abnormality will provide clues for future studies that could develop guidelines to protect these children from excess morbidity (and maybe mortality) due to infections. Such guidelines could include clinical follow-up strategies, prescribing prophylactic antibiotics, or even a procedure to restore T-cell lymphopenia by replacing thymic tissue with a thymic transplant. ${ }^{40,74}$

To better understand the frequency and nature of immune dysfunction in CHARGE syndrome, a prospective study is needed to systematically collect immunological data on more patients with CHARGE syndrome, including those without overt symptoms of immunological defects. Correlating immunological laboratory results with clinical data will yield more insight into the immune dysfunction. In addition, new genome-wide sequencing techniques can be applied to identify patients with atypical CHARGE syndrome and further expand the phenotypic spectrum of CHARGE syndrome, including its immunological features. 


\section{CONCLUSION}

Immunological dysfunction, which predominantly affects T-cell function, has occasionally been described in patients with CHARGE syndrome. A prospective study, with systematically collected immunological and clinical data, is needed to explore the frequency and nature of their immune dysfunction. It would help identify clinical management issues in this infection-prone group of patients.

\section{CONFLICT OF INTEREST}

The authors declare no conflict of interest. NutsOhra Foundation had no role in the study design, data collection and interpretation, or the decision to submit the work for publication.

\section{ACKNOWLEDGEMENTS}

We would like to thank Jackie Senior for editing the manuscript and the NutsOhra Foundation for financial support (project 1202-023) to MTYW.

1 Angelman $\mathrm{H}$ : Syndrome of coloboma with multiple congenital abnormalities in infancy. Br Med J 1961; 1: 1212-1214.

2 Edwards JH, Finlay HVL, Young RB: Coloboma with Multiple Congenital Anomalies Br Med J 1961; 2: 586-587.

3 Hall BD: Choanal atresia and associated multiple anomalies. J Pediatr 1979; 95 : 395-398.

4 Hittner HM, Hirsch NJ, Kreh GM, Rudolph AJ: Colobomatous microphthalmia, heart disease, hearing loss, and mental retardation-a syndrome. J Pediatr Ophthalmol Strabismus 1979; 16: 122-128.

5 Pagon RA, Graham JMJr, Zonana J, Yong SL: Coloboma, congenital heart disease, and choanal atresia with multiple anomalies: CHARGE association. J Pediatr 1981; 99: 223-227.

6 Janssen N, Bergman JE, Swertz MA et al: Mutation update on the CHD7 gene involved in CHARGE syndrome. Hum Mutat 2012; 33: 1149-1160.

7 Blake KD, Davenport SL, Hall BD et al: CHARGE association: an update and review for the primary pediatrician. Clin Pediatr (Phila) 1998; 37: 159-173.

8 Verloes A: Updated diagnostic criteria for CHARGE syndrome: a proposal. Am J Med Genet A 2005; 133: 306-308.

9 Jongmans MC, Admiraal RJ, van der Donk KP et al: CHARGE syndrome: the phenotypic spectrum of mutations in the CHD7 gene. J Med Genet 2006; 43: 306-314.

10 Lalani SR, Safiullah AM, Fernbach SD et al: Spectrum of CHD7 mutations in 110 individuals with CHARGE syndrome and genotype-phenotype correlation. Am J Hum Genet 2006; 78: 303-314.

11 Vissers LE, van Ravenswaaij CM, Admiraal R et al: Mutations in a new member of the chromodomain gene family cause CHARGE syndrome. Nat Genet 2004; 36: 955-957.

12 Bergman JE, Janssen N, van der Sloot AM et al: A novel classification system to predict the pathogenic effects of CHD7 missense variants in CHARGE syndrome. Hum Mutat 2012; 33: 1251-1260.

13 Bergman JE, Janssen N, Hoefsloot LH, Jongmans MC, Hofstra RM, van RavenswaaijArts CM: CHD7 mutations and CHARGE syndrome: the clinical implications of an expanding phenotype. J Med Genet 2011; 48: 334-342.

14 Jyonouchi S, McDonald-Mcginn DM, Bale S, Zackai EH, Sullivan KE: CHARGE (coloboma, heart defect, atresia choanae, retarded growth and development, genital hypoplasia, ear anomalies/deafness) syndrome and chromosome 22q11.2 deletion syndrome: a comparison of immunologic and nonimmunologic phenotypic features. Pediatrics 2009; 123: e871-e877.

15 Comans-Bitter WM, de Groot R, van den Beemd R et al: Immunophenotyping of blood lymphocytes in childhood. Reference values for lymphocyte subpopulations. J Pediatr 1997; 130: 388-393.

16 North KN, Wu BL, Cao BN, Whiteman DA, Korf BR: CHARGE association in a child with de novo inverted duplication (14)(q22->q24.3). Am J Med Genet 1995; 57: 610-614.

17 Theodoropoulos DS: Immune deficiency in CHARGE association. Clin Med Res 2003; 1: 43-48.

18 Kaliakatsos M, Giannakopoulos A, Fryssira $\mathrm{H}$ et al: Combined microdeletions and CHD7 mutation causing severe CHARGE/DiGeorge syndrome: clinical presentation and molecular investigation by array-CGH. J Hum Genet 2010; 55: 761-763.

19 Lonlay-Debeney P, Cormier-Daire V, Amiel J et al: Features of DiGeorge syndrome and CHARGE association in five patients. J Med Genet 1997; 34: 986-989.

20 Markert ML, Alexieff MJ, Li J et al: Postnatal thymus transplantation with immunosuppression as treatment for DiGeorge syndrome. Blood 2004; 104: 2574-2581.

21 Markert ML, Alexieff MJ, Li J et al: Complete DiGeorge syndrome: development of rash, Iymphadenopathy, and oligoclonal T cells in 5 cases. J Allergy Clin Immunol 2004; 113: $734-741$.
22 Janda A, Sedlacek P, Mejstrikova E et al: Unrelated partially matched lymphocyte infusions in a patient with complete DiGeorge/CHARGE syndrome. Pediatr Transplant 2007; 11: 441-447.

23 Gennery AR, Slatter MA, Rice J et al: Mutations in CHD7 in patients with CHARGE syndrome cause T-B+natural killer cell+severe combined immune deficiency and may cause Omenn-like syndrome. Clin Exp Immunol 2008; 153: 75-80.

24 Boudny P, Kurrer MO, Stamm B, Laeng RH: Malakoplakia of the colon in an infant with severe combined immunodeficiency (SCID) and charge association. Pathol Res Pract 2000; 196: 577-582.

25 Wood DJ, David TJ, Chrystie IL, Totterdell B: Chronic enteric virus infection in two T-cell immunodeficient children. J Med Virol 1988; 24: 435-444.

26 Markert ML, Boeck A, Hale LP et al: Transplantation of thymus tissue in complete DiGeorge syndrome. N Engl J Med 1999; 341: 1180-1189.

27 Markert ML, Sarzotti M, Ozaki DA et al: Thymus transplantation in complete DiGeorge syndrome: immunologic and safety evaluations in 12 patients. Blood 2003; 102 1121-1130.

28 Rice HE, Skinner MA, Mahaffey SM et al: Thymic transplantation for complete DiGeorge syndrome: medical and surgical considerations. J Pediatr Surg 2004; 39: 1607-1615.

29 Writzl K, Cale CM, Pierce CM, Wilson LC, Hennekam RC: Immunological abnormalities in CHARGE syndrome. Eur J Med Genet 2007; 50: 338-345.

30 Sanka M, Tangsinmankong N, Loscalzo M, Sleasman JW, Dorsey MJ: Complete DiGeorge syndrome associated with CHD7 mutation. J Allergy Clin Immunol 2007; 120: 952-954.

31 Hoover-Fong J, Savage WJ, Lisi E et al: Congenital T cell deficiency in a patient with CHARGE syndrome. J Pediatr 2009; 154: 140-142.

32 Chopra C, Baretto R, Duddridge M, Browning MJ: T-cell immunodeficiency in CHARGE syndrome. Acta Paediatr 2008; 98: 408-412.

33 Inoue $\mathrm{H}$, Takada $\mathrm{H}$, Kusuda $\mathrm{T}$ et al: Successful cord blood transplantation for a CHARGE syndrome with CHD7 mutation showing DiGeorge sequence including hypoparathyroidism. Eur J Pediatr 2010; 169: 839-844.

34 Assing K, Nielsen C, Kirchhoff M, Madsen HO, Ryder LP, Fisker N: CD4 CD31 recent thymic emigrants in CHD7 haploinsufficiency (CHARGE syndrome): A case. Hum Immunol 2013; 74: 1047-1050.

35 Markert ML, Majure M, Harville TO, Hulka G, Oldham K: Severe laryngomalacia and bronchomalacia in DiGeorge syndrome and CHARGE association. Pediatr Pulmonol 1997; 24: 364-369.

36 Markert ML, Hummell DS, Rosenblatt HM et al: Complete DiGeorge syndrome: persistence of profound immunodeficiency. J Pediatr 1998; 132: 15-21.

37 Squires LA, Dieffenbach AZ, Betz BW: Three malformation complexes related to neural crest development. Brain Dev 1998; 20: 183-185.

38 Lee KD, Okazaki T, Kato Y, Lane GJ, Yamataka A: Esophageal atresia and tracheo-esophageal fistula associated with coarctation of the aorta, CHARGE association, and DiGeorge syndrome: a case report and literature review. Pediatr Surg Int 2008; 24: 1153-1156.

39 Corsten-Janssen N, Saitta SC, Hoefsloot LH et al: More clinical overlap between 22q11.2 deletion syndrome and CHARGE syndrome than often anticipated. Mol Syndromol 2012; 4: 235-245.

40 Gennery AR: Immunological aspects of 22q11.2 deletion syndrome. Cell Mol Life Sci 2012; 69: 17-27.

41 McDonald-McGinn DM, Sullivan KE: Chromosome 22q11.2 deletion syndrome (DiGeorge syndrome/velocardiofacial syndrome). Medicine (Baltimore) 2011; 90: $1-18$.

42 Finocchi A, Di Cesare S, Romiti ML et al: Humoral immune responses and CD27+ B cells in children with DiGeorge syndrome (22q11.2 deletion syndrome). Pediatr Allergy Immunol 2006; 17: 382-388.

43 Gennery AR, Barge D, O'Sullivan JJ, Flood TJ, Abinun M, Cant AJ: Antibody deficiency and autoimmunity in 22q11.2 deletion syndrome. Arch Dis Child 2002; 86: $422-425$.

44 Patel K, Akhter J, Kobrynski L et al: Immunoglobulin deficiencies: the B-lymphocyte side of DiGeorge Syndrome. J Pediatr 2012; 161: 950-953.

45 Björk AH, Oskarsdottir S, Andersson BA, Friman V: Antibody deficiency in adults with 22q11.2 deletion syndrome. Am J Med Genet A 2012; 158A: 1934-1940.

46 Jawad AF, McDonald-Mcginn DM, Zackai E, Sullivan KE: Immunologic features of chromosome 22q11.2 deletion syndrome (DiGeorge syndrome/velocardiofacial syndrome). J Pediatr 2001; 139: 715-723.

47 McLean-Tooke A, Spickett GP, Gennery AR: Immunodeficiency and autoimmunity in 22q11.2 deletion syndrome. Scand J Immunol 2007; 66: 1-7.

48 Quiros-Tejeira RE, Ament ME, Heyman MB et al: Variable morbidity in alagille syndrome: a review of 43 cases. J Pediatr Gastroenterol Nutr 1999; 29 431-437.

49 Le Friec G, Sheppard D, Whiteman P et al: The CD46-Jagged1 interaction is critical for human TH1 immunity. Nat Immunol 2012; 13: 1213-1221.

50 Scheuerle AE, Good RA, Habal MB: Involvement of the thymus and cellular immune system in craniofacial malformation syndromes. J Craniofac Surg 1990; 1: 88-90.

51 Niikawa N, Kuroki Y, Kajii T et al: Kabuki make-up (Niikawa-Kuroki) syndrome: a study of 62 patients. Am J Med Genet 1988; 31: 565-589.

52 Schulz Y, Freese L, Manz J et al: CHARGE and Kabuki syndromes: A phenotypic and molecular link. Hum Mol Genet 2014; 23: 4396-4405.

53 Hoffman JD, Ciprero KL, Sullivan KE et al: Immune abnormalities are a frequent manifestation of Kabuki syndrome. Am J Med Genet A 2005; 135: 278-281.

54 Chrzanowska KH, Krajewska-Walasek M, Kus J et al: Kabuki (Niikawa-Kuroki) syndrome associated with immunodeficiency. Clin Genet 1998; 53: 308-312. 
55 Ming JE, Russell KL, McDonald-McGinn DM, Zackai EH: Autoimmune disorders in Kabuki syndrome. Am J Med Genet A 2005; 132A: 260-262.

56 Randall V, McCue K, Roberts C et al: Great vessel development requires biallelic expression of Chd7 and Tbx1 in pharyngeal ectoderm in mice. J Clin Invest 2009; 119: 3301-3310.

57 Hurd EA, Poucher HK, Cheng K, Raphael Y, Martin DM: The ATP-dependent chromatin remodeling enzyme $\mathrm{CHD7}$ regulates pro-neural gene expression and neurogenesis in the inner ear. Development 2010; 137: 3139-3150.

58 van Bueren KL, Papangeli I, Rochais F et al: Hes 1 expression is reduced in Tbx1 null cells and is required for the development of structures affected in 22q11 deletion syndrome. Dev Biol 2010; 340: 369-380.

59 Aramaki M, Kimura T, Udaka T et al: Embryonic expression profile of chicken $\mathrm{CHD7}$, the ortholog of the causative gene for CHARGE syndrome. Birth Defects Res A Clin Mol Teratol 2007; 79: 50-57.

60 Sanlaville D, Etchevers HC, Gonzales M et al: Phenotypic spectrum of CHARGE syndrome in fetuses with CHD7 truncating mutations correlates with expression during human development. J Med Genet 2006; 43: 211-217.

61 Poliani PL, Facchetti F, Ravanini M et al: Early defects in human T-cell development severely affect distribution and maturation of thymic stromal cells: possible implications for the pathophysiology of Omenn syndrome. Blood 2009; 114: 105-108.

62 Osborne BA, Minter LM: Notch signalling during peripheral T-cell activation and differentiation. Nat Rev Immunol 2007; 7: 64-75.

63 Dongre A, Surampudi L, Lawlor RG et al: Non-canonical Notch signaling drives activation and differentiation of peripheral CD4(+) T cells. Front Immunol 2014: 5: 54 .

64 Palacios R, Goni J, Martinez-Forero I et al: A network analysis of the human T-cell activation gene network identifies JAGGED1 as a therapeutic target for autoimmune diseases. PLoS One 2007; 2: e1222.
65 Campese AF, Grazioli $P$, de Cesaris $P$ et al: Mouse sertoli cells sustain de novo generation of regulatory $T$ cells by triggering the notch pathway through soluble JAGGED1. Biol Reprod 2014; 90: 53.

66 Engelen E, Akinci U, Bryne JC et al: Sox2 cooperates with Chd7 to regulate genes that are mutated in human syndromes. Nat Genet 2011; 43: 607-611.

67 Numakura C, Kitanaka S, Kato M et al: Supernumerary impacted teeth in a patient with SOX2 anophthalmia syndrome. Am J Med Genet A 2010; 152A: 2355-2359.

68 Jongmans MC, Ravenswaaij-Arts CM, Pitteloud N et al: CHD7 mutations in patients initially diagnosed with Kallmann syndrome-the clinical overlap with CHARGE syndrome. Clin Genet 2009; 75: 65-71.

69 Layman WS, Hurd EA, Martin DM: Reproductive dysfunction and decreased GnRH neurogenesis in a mouse model of CHARGE syndrome. Hum Mol Genet 2011; 20: 3138-3150.

70 Yu T, Meiners LC, Danielsen K et al: Deregulated FGF and homeotic gene expression underlies cerebellar vermis hypoplasia in CHARGE syndrome. Elife 2013; 2: e01305.

71 Byrd VM, Kilkenny DM, Dikov MM et al: Fibroblast growth factor receptor-1 interacts with the T-cell receptor signalling pathway. Immunol Cell Biol 2003. 81: 440-450.

72 Zentner GE, Layman WS, Martin DM, Scacheri PC: Molecular and phenotypic aspects of CHD7 mutation in CHARGE syndrome. Am J Med Genet A 2010; 152A: 674-686.

73 Piliero LM, Sanford AN, McDonald-McGinn DM, Zackai EH, Sullivan KE: T-cell homeostasis in humans with thymic hypoplasia due to chromosome 22q11.2 deletion syndrome. Blood 2004; 103: 1020-1025.

74 Markert ML, Devlin BH, McCarthy EA: Thymus transplantation. Clin Immunol 2010; 135: 236-246.

75 Wincent J, Holmberg E, Strömland K et al: CHD7 mutation spectrum in 28 Swedish patients diagnosed with CHARGE syndrome. Clin Genet 2008; 74: 31-38.

Supplementary Information accompanies this paper on European Journal of Human Genetics website (http://www.nature.com/ejhg) 